\title{
State and prospects for the development of thick-seam mining technology in the southern Kuzbass
}

\author{
Anastasia Vargolskikh* \\ T.F. Gorbachev Kuzbass State Technical University, Kemerovo, 650000, Russia
}

\begin{abstract}
The paper discusses the factors that limit the growth of coal production in Kuzbass. They were identified by the results of statistical analysis of the actual production indicators of working faces in eight thick coal seams. Technological solutions for the rational control of hard-tobreak roof rocks, the shape and size of coal pillars, which ensure the stability of protected workings and isolation of the worked-out area from endogenous fires, are substantiated.
\end{abstract}

\section{Introduction}

The Russian Federation ranks second in the world in terms of coal reserves. According to various sources, from 17.6 to $18.2 \%$ of this mineral is concentrated in our country. In absolute figures, this is over 157 billion tonnes (107.9 billion tonnes of lignite coal and 49.1 billion tonnes of hard coal). Coal reserves are concentrated in 22 basins and 129 separate deposits and not all of them have industrial importance. Most of the coal enterprises are concentrated in Siberia and the Far East [1]. Most of the coal deposits in Kuzbass are of multiseam nature. The average thickness of the coal seams in the basin is $4 \mathrm{~m}$. There are significant reserves of coal -31.8 billion tonnes which can be mined by open-pit mining. The bulk of these coals -19.4 billion tonnes or $60.9 \%$ is concentrated in the seams with a thickness from 3.51 to $15 \mathrm{~m}$; 11.9 billion tonnes (37.5\%) is concentrated in layers from 1.21 to $3.5 \mathrm{~m}$, and 496 million tonnes - in the seams with a thickness of over $15 \mathrm{~m} \mathrm{[2].}$

\section{Statistical data analysis}

The statistical analysis of the daily production volumes based on the operation results of eight faces in the thick seams of the mines in Tom-Usinskoye and Erunakovskoye fields are shown in fig. 1. As it follows from the graphs, the daily production volumes vary in wide ranges. This is confirmed by the coefficients of variation $V$, calculated according to [3] by the formula:

$$
V=\frac{s}{x} 100 \%
$$

\footnotetext{
* Corresponding author: nastavargolskih02326@gmail.com
} 
where $\mathrm{s}$ is the standard deviation, $\mathrm{t} /$ day;

$\bar{x}-$ is the average value of the investigated indicator, $\mathrm{t} / \mathrm{day}$.

According to calculations using formula (1), it was found that the coefficient of variation increases from 33 to $59 \%$ with an increase in seam thickness that is, the seam thickness is a factor that determines the level of production and industrial safety. The obtained results of statistical processing of the faces productivity indicators confirm the importance of research into the technology of mining flat thick seams in order to substantiate innovative technological solutions ensuring improvement in the operational stability of mines in general.

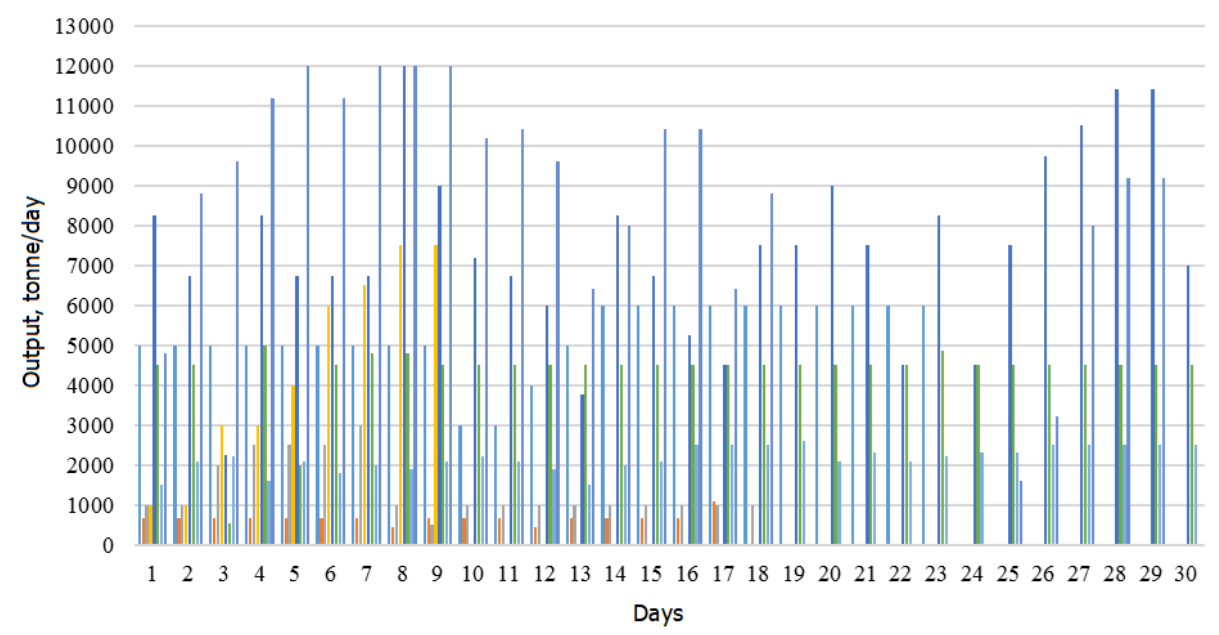

- Olzherasskaya-Novaya Mine, seam $21, \mathrm{~m}=5.88-8.95 \mathrm{~m}$, gas fat lean coal

- Osinnikovskaya Mine, seam E- $5, \mathrm{~m}=3.05-4.10 \mathrm{~m}$, fat coal

- Raspadskaya Mine, seam 7-7a, $\mathrm{m}=3.97-3.90 \mathrm{~m}$, gas fat coal

- Sibirginskaya Mine, seam $\mathrm{III}, \mathrm{m}=7.40-10.65$, coking, meager caking coal

- Alardinskaya Mine, seam $6, \mathrm{~m}=7.68-9.47 \mathrm{~m}$, coking caking coal

- Uskovskaya Mine, seam $48, \mathrm{~m}=2.41-5.71 \mathrm{~m}$, gas fat coal

- Raspadskaya-Koksovaya Mine, seam III, $\mathrm{m}=8.20-12.35 \mathrm{~m}$, coking coal

- Raspadskaya Mine, seam 6-6a, $\mathrm{m}=4.49-4.53 \mathrm{~m}$, gas fat coal

Fig. 1. Daily production from working faces in seams with a capacity of $m>3.5 \mathrm{~m}$.

\subsection{Evaluation of the results of qualitative and quantitative analysis of performance indicators}

The following factors that negatively affect the capacity and safety of mining operations were identified based on the results of a qualitative and quantitative analysis of the performance of working faces in thick seams $[4,5]$ :

- caving of the band located between the slices during the development of the bottom slice in the conditions of mining a thick coal seam by multi-slice method;

- stoppage of the production face during preventive measures against dynamic condition and endogenous fires;

- spontaneous-combustion liability of coals;

- the presence of hard-to-break rocks in the geological strata;

- inporased stress concentration in the edge sections of seams and in coal pillars. 
The analysis of processes and operations under the negative influence of the indicated factors was carried out and the directions for improving the mining technology of thick coal seams were identified.

\section{Analysis of the recommended measures}

It is proposed to replace a set of local measures, carried out in the operation area of highperformance machines with their obligatory stoppage prescribed by the safety regilations, with regional measures carried out in advance.

For example, to bring a rock massif into a safe state it is necessary to use regional (remote) methods with constant monitoring the massif stress-strain state by multifunctional safety system, with subsequent interpretation of the results of unloading effect on the massif and issuing a permit to resume mining operations [6]. Geophysical methods of monitoring the measures effectiveness should be applied for implementation of the regional methods of rock mass unloading [7]. The difficulty of mining thick flat coal seams prone to endogenous fires with division into inclined, horizontal or transversely inclined slices lies in the need to leave the solid for various purposes to protect and maintain workings that contour the excavation unit and isolate the worked-out space on slice. Therefore, an option is proposed for the development of thick coal seams with the roof coal release into the face space of the lower slice [5]. The effectiveness of this development system has been practically proven in the mines of China and Russia. When mining coal seams with the release of roof coal, the number of pillars is reduced, but a solid is left between adjacent excavation pillars, the width of which can be determined according to the current methodological documents.

\section{Conclusion}

Thus, in order to increase the stability of coal extraction from working faces, it is recommended:

- to implement measures for unloading the rocks massif in advance without interrupting the high-performance equipment operation;

- increase the level of industrial safety and reduction of the level of negative manifestations of increased rock pressure using the method of directional hydraulic fracturing of hard-to-break rocks of the main roof, when the mechanized complex exits the assembly chamber. Carrying out measures to soften the seam roof when performing a set of works in the production face;

- optimize the parameters and designs of torpedo charges when placing them from the surface into the operating technical wells of the extraction area prepared for development. Analysis and technological assessment of the results obtained when conducting advanced torpedoing from the surface;

- to prevent coal from being squeezed out of the working soil by means of the formation of an unloading slot by drilling and blasting;

- partial preservation of the preparatory workings of the upper layer, by installing crib, advancing the support of workings, according to the recommendations developed by specialized institutes.

- regular visual and instrumental examination of workings for the presence of vertical and horizontal displacements of the section at control points. After analyzing the results obtained, measures are developed for the safe conduct of mining operations.

- application of the development system at full thickness with the release of roof coal to the conveyor of the lower slice. 


\section{References}

1. Coal mining in Russia www.gruntovozov.ru

2. Large archive of documents. Most of the coal deposits in Kuzbass are multiseam www.odnopartiec.ru/5464

3. V.G. Minashkin, et al, Theory of Statistics (EAOI, Moscow, 2008)

4. S.I. Kalinin, et al, Development of a thick coal seam by a mechanized complex with the release of an under-roof unit (KuzSTU, Kemerovo, 2011)

5. V.I. Klishin, MIAB, 6, 36-47 (2014)

6. V.M. Vernigor, Neftegaz.RU, 10 (2019) www.magazine.neftegaz.ru

7. D.V. Yakovlev, et al, Guidelines for the creation of systems for monitoring the state of a rock massif and forecasting rock bumps as elements of a multifunctional safety system for coal mines (St. Petersburg: VNIMI, 2012) 